\title{
Design and Narrative for Deaf and Listener Children
}

\author{
Cristina Portugal \\ PUC-Rio \\ Av. General Felicíssimo Cardoso, 835 \\ - bloco 2 - apto 701, Barra \\ CEP 22631-360, Brazil \\ crisportugal@gmail.com
}

\author{
Eliane Jordy \\ PUC-Rio \\ Rua Senador Vergueiro, 238 - apto \\ 411, Flamengo \\ CEP 22230-001, Brazil \\ eliane.jordy@gmail.com
}

Felipe Alram

UFRJ

Av. General Felicíssimo Cardoso, 835

- bloco 2 - apto 701, Barra

CEP 22631-360, Brazil

crisportugal@gmail.com

\author{
Ana Correia \\ PUC-Rio \\ Rua Almirante Cochrane, 88/501 - \\ 411, Flamengo \\ CEP 22230-00, Brazil \\ anacorreia@globo.com
}

\begin{abstract}
This essay is part of an undergoing investigation of interdisciplinary nature between the fields of Design and Assisted Technology. Starting from the principle based in Kerckhove (1998) ideas, that each technology extends one of our faculties and transcends our physical limitations, we want to get the best extensions of our body. The focus of this study is to produce an interactive book in bilingual digital format (Brazilian Sign Language - LIBRAS and Portuguese) by means of an investigation encompassing relations of design, information technology and communication. The aim, thus, is the development of a hypermedia environment that helps the process of reading for deaf children, but not exclusively. In this paper will be presented a summary of the methodological process in which the research is founded, and part of the first stage of investigation, in other words, the study of similar and the foundation for developing the narrative envisioning an adequate project of visual, verbal and sound language in order to collaborate with the process of interpretation and construction of the meaning of information that will be made available. The research project encompassing this study was funded by Brazilian development agencies, the National Council of Scientific and Technological Development, an agency of Brazil's Ministry of Science, Technology (CNPq) and Innovation and Foundation for Research Support of the State of Rio de Janeiro (Faperj). The intention of this study is to found and develop means that enable relationships between knowledge about necessities and potentialities of deaf children and to make available a book that might stimulate their development and, in consequence, facilitate their inclusion in society.
\end{abstract}

Design. Narrative. Media. Technology. Inclusion.

\section{INTRODUCTION}

This paper presents a research project about creating an e-book for deaf children based on a bilingual perspective. It is supported by the National Council of Scientific and Technological Development, an agency of Brazil's Ministry of Science, Technology and Innovation and Foundation for Research Support of the State of Rio de Janeiro (FAPERJ). It has been developed by the team of the Interdisciplinary Laboratory of Design/Education from the Department of Arts \& Design from the Pontifical Catholic University of Rio de Janeiro, Brazil.
Its main attributions are to promote scientific and technological research and to stimulate researcher training in the country. The intention of this research is to create an e-book for children with interactivity possibilities, comprising scenes narrated in Brazilian Signs Language (LIBRAS) and in written Portuguese. The stories awaken creativity and create unique scenes and emotions in the imagination, developing the cognition. Through them it is possible to make analogies, learn new words, become more familiar with the language, build relationships and interpret the narrative. 
This investigation being developed has an interdisciplinary character, involving the fields of Design and Assistive Technology, which is an area of knowledge comprising products, methodologies, strategies, practices and services aiming to promote functionality, related with activity and participation of people with deficiencies, incapacities or reduced mobility, aiming their autonomy, independence, quality of life and social inclusion. (ATA VII/CAT, in: Portugal 2013).

Using the words of Kerckhove (1998), it is assumed that, as each technology extends one of our faculties and transcends our physical limitations, we wish to acquire the best extensions for our body. It seems to us that our machines, be them a machine or a computer, have powers much above the use that we can make of them. Digital technology brings new possibilities of inclusion for people with special needs in society. Deficiency is not an attribute of the person, but a complex set of conditions, many of them created by the social environment. In consequence, the solution of the problem demands one action and is the responsibility of society to make the necessary changes for the full participation of people with deficiency in areas of social life. However, the question is one of attitude or ideology about social changes, while at the political level it is a question of human rights. (ATA VII/CAT, in: Portugal 2013).

In face of the exposed, it becomes fundamental to develop means that enable relations between the knowledge about needs and potentials of children with special needs and tools, equipments and/or toys that may stimulate their development and, in consequence, easing their inclusion in society. We may consider that the approach is essentially double. In other words, on the one hand it is essential to know the needs and restrictions, on the other hand, it is also essential to research and find the elements which allow to solve the problem, being this lack of models one of the main gaps to be solved in most of the schools.

The complexity of connection between Sign Language and Portuguese is a challenge in bilingual education projects, as - despite being a native language - in Sign Language verbs are not conjugated, nor are prepositions or connectives used, making the process of literacy in Portuguese in the form of a written language difficult in relation to Sign Language, as a spoken language.

Taking as a base the ideas outlined above, the focus of this study is to produce an educational material in the form of an interactive bilingual e- book (LIBRAS and Portuguese) by means of an investigation comprising relations of Design in Teaching-Learning Situations. The goal, thus, is to develop a e-book where the narrative will be through the multiple languages available in hypermedia systems. To support this idea, Bendrix mentions:

According to research done by Nikolopoulos, Lloyd, Starczewski and Gallaway, narrative skills constitute an important area of linguistic and communicative development. For the developing child, narratives provide a bridge between the highly conceptualised language of home and the decontextualised language of educational settings from an early age. (Bendrix 2013, p. 1).

This paper presents the methodological process in which the research is based, and starts from the first stage of investigation, in other words, the study of similar works and the foundation for the narrative development. It is aimed to identifying the possibilities of interaction of design resources in hypermedia projects, analysing and identifying the value of each one helping the motivation, ludic aspect and immersion; investigating questions involving digital systems, such as interactivity; visualisation of complex data in digital environments; software and narrative constructions in digital media; and the impacts of digital technology in the contemporaneous society; investigating how design methods and techniques and their applicability in digital systems may collaborate for the learning and teaching process, consequently, easing the building of knowledge.

As a result, the project will present a theoretical research aligned with the foundations for the development of hypermidiatical educational environments. Furthermore, an interactive e-book for tablets or similar will be produced. In it, the narrative will be presented by the multiple languages that converge in hypermidiatical environments.

\section{RESEARCH METHODOLOGY}

The methodology adopted by Couto et al. (2014) has a qualitative approach and is being developed as an exploratory research, as a case study. According to other sources that will found the theme, a literature and documental research, critical reading and analysis of texts, interviews with students and teachers which will be part of the practical experiences, among other techniques are being developed. 


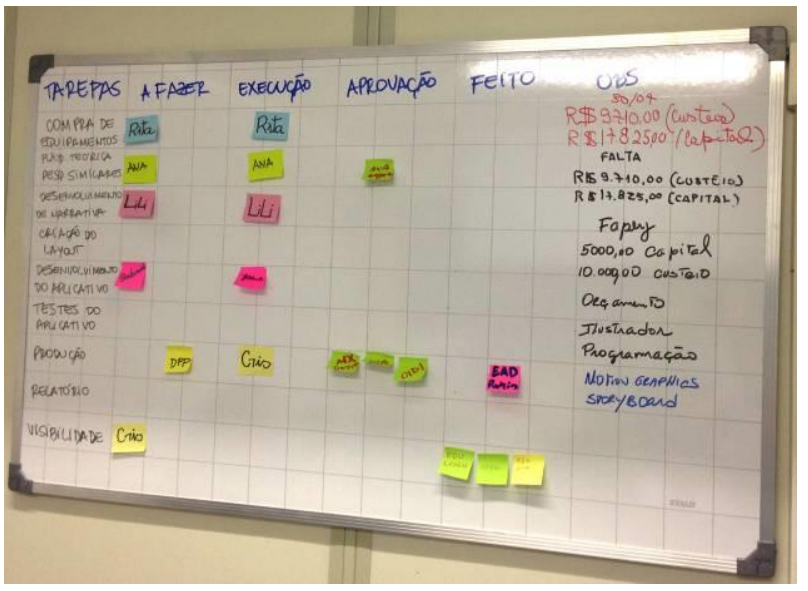

Figure 1: Kaban board

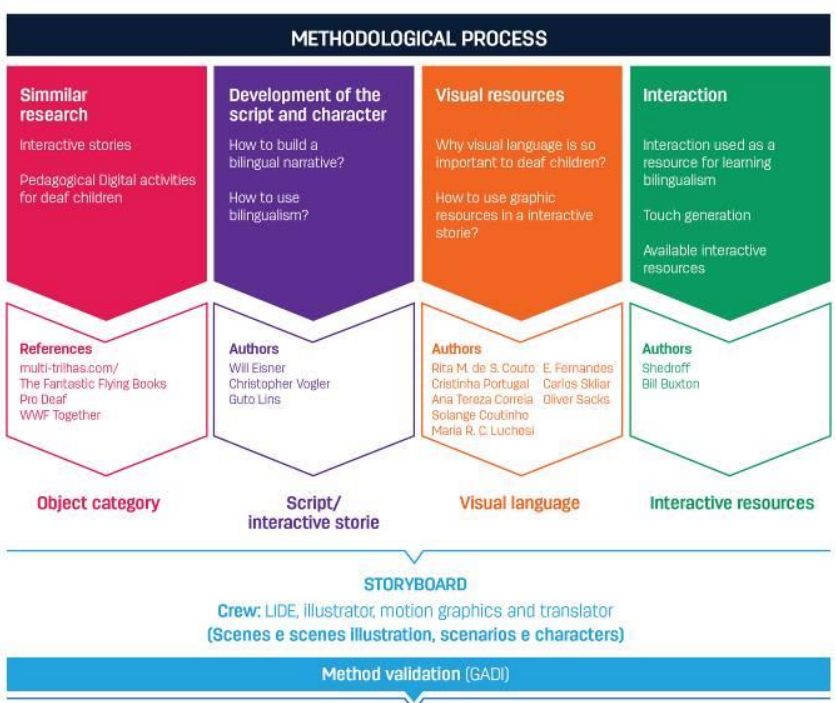

DEVELOPMENT

Crew: LIDE, illustrator, motion graphics, trans ator and web developer

(Software development motion graphics, interactive resources, usability and accessibility - prototype)

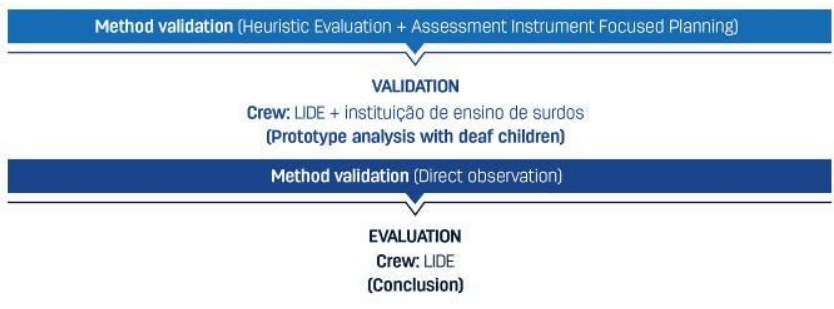

Figure 2: Methodological process of research

\section{STUDIES OF SIMILAR WORK}

After the first steps of bibliographical research for deepening the project problem, the research foundation underwent an analysis of similar works in order to allow a higher approximation with the developed research object - the digital book - and with the target audience, children from six years old. Thus, several objects were comparatively analysed for verifying similarities and affinities between them, as well as, a single object could be studied in different points. The studies of similar works became an important stage for knowing other objects which may contribute for the research.

In order to illustrate this paper, the application books "Fantastic Flying Books" of Mr.Morris Lessmore" where selected.

It is an app book inspired by hurricane Katrina, Buster Keaton and the "Wizard of Oz". It has a narrative appeal with relevant content. The application enable the readers to have an exciting reading experience by accessing augmented reality resources. The reader executes tasks and interacts with the history in order to unblock the content. The application is compatible with iPad 2, 3 and iPhone. (The expanded on similar study can be seen in Portugal et al. (2015) paper).

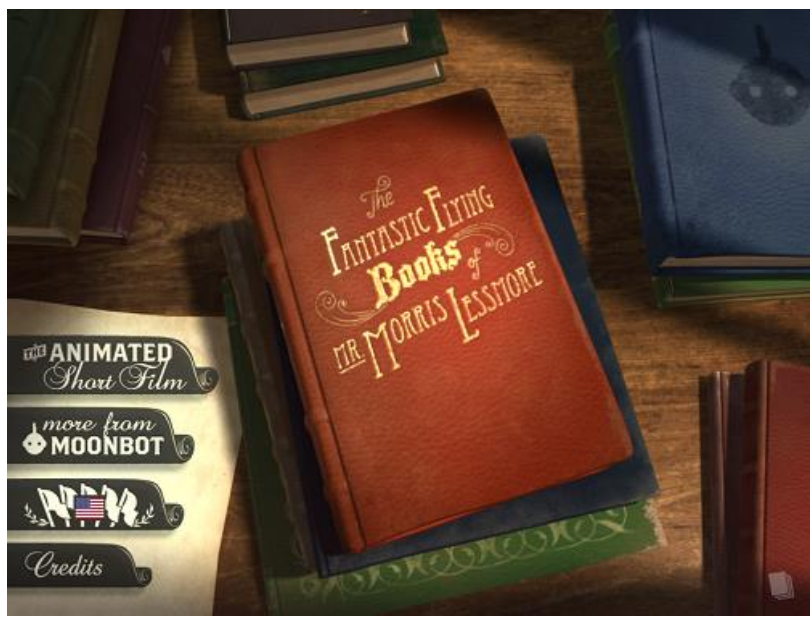

Figure 3: pages from the app book "Fantastic Flying Books" of Mr. Morris Lessmore

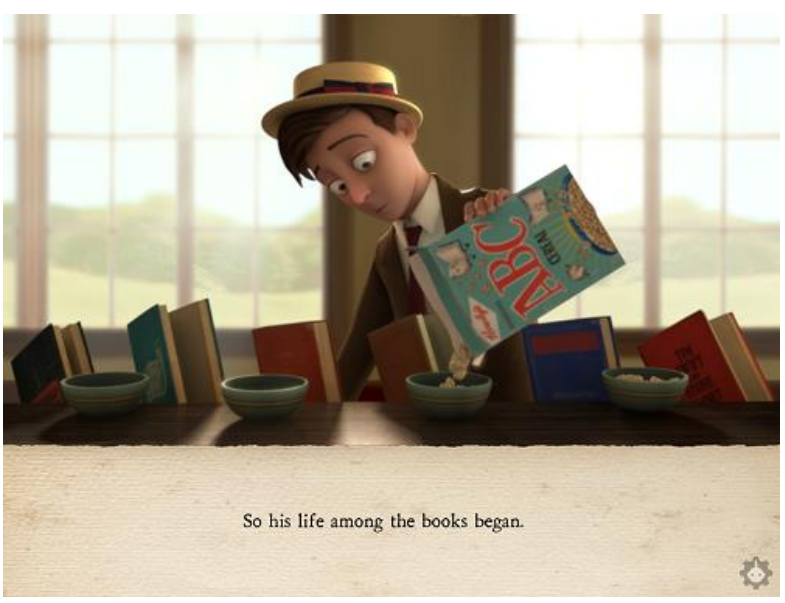

Figure 4: pages from the app book "Fantastic Flying Books" of Mr. Morris Lessmore

\section{ABOUT DIGITAL NARRATIVE}

Although in this paper the focus is on the discussion of a narrative created for the elaboration of a book in digital format, the changes that happened with the advent of information and 
communication technologies are also contemplated.

In the combination between storytelling with resources of digital technologies, the narratives are elaborated under the perspective of multiple languages, allowing that text, photography, video, audio and graphics are digitally translated and may be simultaneously visualised.

The digital format is called by Lev Manovich (2001) of New Media. The author refers to it as the convergence of two historically parallel technologies: computing technology and media technology.

From the digital crossing between devices and medias, comes the possibility of creating new ways of narratives, generating dynamic compositions and the development of a new aesthetics.

Regarding the use of New Media, Manovich (2011) claims to be necessary the creation of an aesthetical theory that is able to be founded in still undiscovered elements, the aesthetic of a structure that is still not considered, according to him, a language.

This study presents some theoretical foundations underlying the creation of an interactive narrative which supports this new language enabled by the convergence of media.

In face of the need for a specific narrative for the digital book for deaf and hearing children, we started from the idea defended by Portugal (2010), when she says that the difficulties and questions of communication of the child with deafness that expresses itself by the sign language, must be worked since the early age, so that its needs are not neglected.

Pushed to the sidelines of social, educational and cultural questions, it has been a challenge the acquisition of language by deaf subjects since, most of the times, the access to it is nonexistent. For that, the cognitive development of the deaf child demands an environment where the Brazilian Sign Language ("LIBRAS") is present from an early age, as well as the written and spoken Portuguese.

In this investigation we considered the digital narrative as a promising mean for inclusion of deaf children in society, since it organises the thinking and enables several ways of watching the world. In this sense, the interactive digital book aimed to deaf child, object of this study, may be seen as an ally of this process, propitiating that the deaf child can enjoy the universe of reading.

The digital format was used as the starting point for the development of narrative due to its characteristic of convergence of languages, easing the visual-spatial comprehension of the history. The narrative aims to reach the hearing children, illuminating both the book object as well as the reader leaning over it - through an experience that includes the hearing and the deaf readers, on the use that they make of the language.

The proposal of the narrative of the digital book for deaf and hearing children aims to offer possibilities for each reader to follow its own time and space, since our "perceptions of time and space are not, as we believed, absolute truths. Those entrances are made by means of hyperlinks that allow the reader builds a way through the environment and content according to its own will. As recognised by Murray (2003), stories written in hypertext normally have more than one entry point, several internal branches and no clear-cut end. (Murray 2003, p. 65).

The narrative of the digital book highlights mainly objects and environments. Its scenario is a neighbourhood in the city of Rio de Janeiro, the Cosme Velho. The narrative is sequenced, contains the beginning, development of events, a climax and an end suggesting a new beginning. Despite a realistic figuration, the narrative brings elements of fantasy that allow the protagonists two children of different races and characteristics, one deaf and the other hearing - to know each other and become friends.

LIBRAS is the first language of the deaf, being written Portuguese the second one, according to orientation of bilingual literacy. The grammar of LIBRAS differs from the Portuguese grammar, because it does not use prepositions, articles and there is no verb conjugation. In this sense, the development of the narrative of the digital book proposed had to be adapted in order to support LIBRAS. Besides, inside a text there must be elements that establish a link between the parts. In the digital book under development, the narrative had this role of having significant links that made the cohesion of the written text, allying it to sound and images.

For Murray (2003) the narrative universe and shapes progress with the evolution of the means of communication and expression, as well as with the use that we make of the new technologies.

The shape of digital history that will emerge will encompass many different formats and styles, but it will be, essentially, unique and unmistakable entity. It will not be an interactive "this" or "that", although most this shape may be extracted from tradition, but a reinvention of the act of history telling itself for the new digital medium (Murray 2003, p. 236).

Also according to the author, the several digital devices, connected in networks act as a telephone, by offering person-to-person communication in real time; as a television, by transmitting movies; an auditorium, by bringing together groups for speeches and discussions; a library, by offering a 
large number of reference texts; a museum, in its ordered presentation of visual information; as a dash board, a radio, a board for games and, even, as a manuscript, by reinventing the rolls of texts of the parchments. All the main ways of representation from the first five thousand years of human history are already translated for the digital medium (Murray 2003, p.41).

According to Vilches (2003), "each medium has its own criteria of pertinence and for semanticising its languages; on the other hand, each language depends on a specific support, to express itself" (Vilches 2003, p. 244), in other words, the exploration of resources and languages of each platform and the complementarity of contents between them may open, to the reader, several narrative possibilities.

In face of this context, the proposed work had the goal of guiding the narrative process in a ludic way, organising a self language and aesthetic for the medium, using current platforms such as tablets and smartphones, allowing deaf and listening children to manage the narrative, when being displaced by the narrative world, by self initiative, building a personal interpretation of history Thus, the link between a scene and another is built by the child reading and by means of links that offer different paths to it, turning that reading not only in an activity with an end in itself - mechanical and decontextualised. (Murray 2003, p. 237).

Approximating the child to the universe of books, in an open way, is a question of compromise that Education must have. Fanny Abramovich, Brazilian writer of children's literature, tells that if the child is the only guilty in adult tribunals by not reading, the verdict of innocent must be asked for, because more guilty yet are the adults that did not offer this contact to it, that do not open to it those - and many other - tracks for walking through the world of letters. (Abramovich 1999, p.163)

In the construction of formal, functional, subjective and methodological relationships of this project is predicted, to think and evolve the configuration and organisation of information - be it verbal, visual, sounds, kinesthetic, of interaction or navigation from the hypermedia as a language with different and specific characteristics that allow the visualisation of data that will influence directly the aesthetic, creative and informational conception of the interactive digital book.

\section{THE NARRATIVE PLACE}

The story unfolds in Cosme Velho, one of the many neighborhoods in Rio de Janeiro, developed in the highest grounds of the Carioca River. The scenario's choice came from the idea to present a square located in Cosme Velho, called Largo do Boticário (or Apothecary Square). This was based upon the historical and cultural relevance of the previously mentioned square. Nowadays, it's a small wooded island in the city's landscape, with its neo colonial facades. Currently in ruins, it needs revitalisation, preserving the architetonic characteristics and the ambience of the location.

One passing by Cosme Velho's neighborhood might not imagine that below its streets, run the waters of the river responsible for the origin of the name given for every citizen born in the city: Carioca. This river has an immeasurable hydric relevance and it is directly attached with the urban development of the city, being the source of potable water for the population during the Colonial Era.

It has been channeled in the beginning of the 20th century, however, its underground waters run as a sewerage line that flows in Baía de Guanabara (Guanabara Bay), specifically at Praia do Flamengo (Flamengo Beach). Only in three sections the old Carioca river runs openly: on its source, inside Floresta da Tijuca (Tijuyca's Forest); on Largo do Boticário (Apothecary Square); and in its outfall, at Praia do Flamengo (Flamengo Beach).

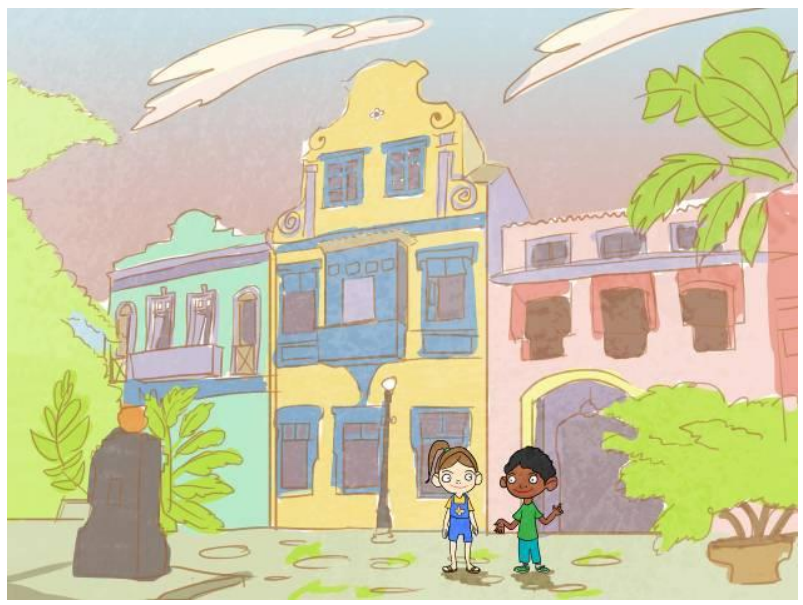

Figure 5: first scenery study

\section{FINAL CONSIDERATIONS}

In recent years, digital technologies is changing the way we learn and experience the world around us; still, there is the need for technologies that meet the needs of specific groups of learners, such as people with different kinds of disabilities. In this particular project, we suggest that the type of interactive e-book we are developing can not only help deaf children to increase their knowledge and abilities, but it can also constitute a tool for social inclusion.

Given the above, we find in interactive narrative the best way to promote learning playful way for deaf 
children without separating them necessarily the possibility of contact with other hearing children during use. Working inspired by Carlos Skliar ideas (1997), that should not be accepted as an impediment to the child's disability, the e-book, the subject of this study, we seek to set up an inclusive object, where disability is seen as difference and not deficit. Skliar says the child does not live from their disability, but from what it results to be a functional equivalent. All this would be as if, now the clinical and therapeutic model not obstinacy both in combat disability, which implies, in general, result in even more social consequences. Rehabilitation, or compensation, that is the question. Persisting against the deficit, this is the error.

Couto et al. (2014) say literacy is a process that transcends the fact of leading the student to verbalise phonemes, words and sentences and write them in isolation mechanically. Literacy is to provide the resources necessary for the child to use the code of reading and writing as an effective means of interaction, and especially communication with their social environment. Therefore, it is important that teachers devise their own situation of learning as an experience, which, if perceived and understood, may provide grounds for them to reflect on the best way to teach the deaf to read and write.

Having as an assumption that activities with the deaf cannot be limited to just a mere work of language acquisition, this study is oriented by a multi-sectorial vision, in other words, the functions by which the deaf receives the impression of external objects such as, for instance, vision and tact are emphasised. Aiming to reach those goals, the digital book will make available for the deaf child a variety of relationship possibilities with the written language and LIBRAS, contributing for the scientific and technological development of the areas of Design and Education, focusing on Special Education.

\section{REFERENCES}

Abramovich, F. (1999) Literatura Infantil: Gostosuras e bobices, 5th edition. Scipione, São Paulo.
ATA VII - Comitê de Ajudas Técnicas - CAT. Available under: http://www.assistiva.com.br. In: Portugal, C., Design, Educação e Tecnologia http://www.design-educacao-tecnologia.com (retrieved 2 January 2013).

Brescia, F. (2011) Literatura em Libras estimula inclusão e desenvolvimento de crianças surdas. Minas Gerais. http://g1.globo.com/minasgerais/noticia/2011/10/literatura-em-libras-estimulainclusao-e-desenvolvimento-de-criancassurdas.html (retrieved 27 June 2015).

Burdek, B. E. (2006) História, teoria e prática do design de produtos. Edgard Blucher, São Paulo.

Couto, R. M. S., Portugal, C., Jordy, E., Correia, A. T. P. S., \& Correa, M. F. G. (2014) Interactive digital book for deaf and listener children. In: EDULEARN14, the 6th annual International Conference on Education and New Learning Technologies. IATED Digital Library, Barcelona.

Kerckhove, D. (1998) Skin of Culture. Kogan Page, London.

Manovich, L. (2001) The Language of New Media. The MIT Press, Massachusetts.

Murray, J. H. (2003) Hamlet no holodeck: o futuro da narrativa no ciberespaço. Itaú Cultural - Unesp, São Paulo.

Portugal, C. (n.d.) Design, Educação e Tecnologia http://www.design-educacao-tecnologia.com (retrieved 14 January 2014).

Portugal, C. (2015) et al. Design in the creation of an interactive e-book for deaf and listening children. In: Proceedings $11^{\text {th }}$ European Academy of Design Conference. Paris Descartes University: Paris.

Portugal, C.; et al. (2013) Proposta de livro interativo digital para crianças surdas. In: IV Simpósio de Pós-Graduação em Design (SPPG Design 2013), Bauru/SP. Anais do IV Simpósio de Pós-Graduação em Design (SPPG Design 2013). Bauru/SP.

Vilches, L. (2003) A migração digital. Loyola, São Paulo. 